\title{
PENGARUH PENAMBAHAN PASIR TERHADAP TINGKAT KEPADATAN DAN DAYA DUKUNG TANAH LEMPUNG BERLANAU (STUDI KASUS : JALAN BANJARPARAKAN - MENGANTI)
}

\section{THE EFFECT OF ADDING SAND ON THE LEVEL OF DENSITY AND CARRYING CAPACITY OF SILLY CLAY SOIL (CASE STUDY: BANJARPARAKAN - MENGANTI ROAD)}

\author{
Fauzia Nur Amrulloh', Amris Azizi ${ }^{2}$ \\ ${ }^{12}$ Program Studi S1 Teknik Sipil, Fakultas Teknik dan Sains \\ Universitas Muhammadiyah Purwokerto
}

\section{Informasi Artikel}

Dikirim, 4 November 2021

Direvisi, 26 Desember 2021

Diterima, 3 Jamuari 2022

\section{Korespondensi Penulis:}

Fauzia Nur Amrulloh Program Studi Teknik Sipil Universitas Muhammadiyah Purwokerto

JL. K.H. Ahmad Dahlan

Purwokerto, 53182

amrissampang11@gmail.com
Daya dukung tanah merupakan hal yang sangat perlu diperhatikan dalam perencanaan pekerjaan konstruksi bangunan maupun jalan. Hal ini dikarenakan tanah berfungsi sebagai media penahan beban dari konstruksi yang ada di atasnya. Stabilisasi menggunakan bahan tambah pasir merupakan salah satu cara untuk memperbaiki daya duukung tanah. Dalam penelitian ini tanah yang distabilisasi adalah jenis tanah lempung berlanau yang berasal dari ruas Jalan Banjarparakan-Menganti pada sta 0+175 sampai 0+225, Kecamatan Rawalo, Kabupaten Banyumas-Provinsi Jawa Tengah. Penelitian ini dilakukan dengan menggunakan campuran pasir dengan variasi campuran $10 \%, 15 \%$, $20 \%$, dan 25\%. Uji dilakukan untuk mendapatkan nilai CBR (California Bearing Ratio), berat jenis, batas- batas Attereberg sampel tanah. Hasil uji diperoleh kadar air optimum $36,1 \%$ dengan kepadatan kering maksimum $1,29 \mathrm{gr} / \mathrm{cm}^{3}$ dan nilai daya dukung tanah sebesar 8,20\% untuk sampel tanah tanpa penambahan pasir. Untuk sampel tanah dengan campuran pasir 10\% diperoleh nilai kadar air optimum 34,5\% dengan kepadatan kering maksimum $1,33 \mathrm{gr} / \mathrm{cm}^{3}$ dan nilai daya dukung tanah sebesar $10 \%$. Untuk sampel tanah dengan campuran pasir $15 \%$ diperoleh nilai kadar air optimum 32,6\% dengan kepadatan kering maksimum $1,35 \mathrm{gr} / \mathrm{cm}^{3}$ dan nilai daya dukung tanah sebesar $11,1 \%$. Untuk sampel tanah dengan campuran pasir $20 \%$ diperoleh nilai nilai kadar air optimum $30,1 \%$ dengan kepadatan kering maksimum $1,37 \mathrm{gr} / \mathrm{cm}^{3}$ dan nilai daya dukung tanah sebesar $12,3 \%$. Untuk sampel tanah dengan campuran pasir $25 \%$ diperoleh nilai nilai kadar air optimum $28,05 \%$ dengan kepadatan kering maksimum $1,39 \mathrm{gr} / \mathrm{cm}^{3}$ dan nilai daya dukung tanah sebesar $12,7 \%$.

Kata Kunci : Tanah lempung berlanau, pasir, daya dukung tanah.

\section{ABSTRACT}

The bearing capacity of the soil is very important in planning the construction of buildings and roads. This is because the soil functions as a load-bearing medium from the construction above it. Stabilization using added sand is one way to improve the bearing capacity of the soil. In this study, the soil that was stabilized was silty clay originating from Jalan Banjarparakan-Menganti at sta $0+175$ to $0+225$, Rawalo District, Banyumas Regency-Central Java Province. This research was conducted using a mixture of sand with a mixed variation of $10 \%, 15 \%, 20 \%$, and $25 \%$. The test was carried out to obtain the CBR (California Bearing Ratio), specific gravity, Attereberg limits of the soil sample. The test results obtained an optimum water content of $36.1 \%$ with a maximum dry density of $1.29 \mathrm{~g} / \mathrm{cm} 3$ and a soil carrying capacity of $8.20 \%$ for the soil sample without the addition of sand. For soil samples with a mixture of $10 \%$ sand, the optimum moisture content value was $34.5 \%$ with a maximum dry density of 1.33 $\mathrm{g} / \mathrm{cm} 3$ and a soil carrying capacity of $10 \%$. For soil samples with a mixture of $15 \%$ sand, the optimum water content value is $32.6 \%$ with a maximum dry density of $1.35 \mathrm{~g} / \mathrm{cm} 3$ and the value of the soil bearing capacity is $11.1 \%$. For soil samples with a mixture of $20 \%$ sand, the optimum water content value was $30.1 \%$ with a maximum dry density of $1.37 \mathrm{gr} / \mathrm{cm} 3$ and a soil bearing capacity of $12.3 \%$. For soil samples with a mixture of 
$25 \%$ sand, the optimum water content value is $28.05 \%$ with a maximum dry density of $1.39 \mathrm{gr} / \mathrm{cm} 3$ and the value of the soil bearing capacity is $12.7 \%$.

Keyword : Silt clay, sand, soil bearing capacity.

\section{PENDAHULUAN}

Tanah merupakan suatu material dasar yang sangat berpengaruh dalam pekerjaan Teknik Sipil, khususnya dalam konstruksi jalan. Tanah sangat berpengaruh karena jalan membutuhkan tanah dasar (subgrade) yang baik yang berfungsi sebagai perletakan lapis perkerasan dan mendukung konstruksi jalan diatasnya. Untuk kekuatan dan keawetan lapisan konstruksi perkerasan jalan, salah satunya tergantung dari sifat-sifat dan daya dukung tanah dasar ini.

Salah satu persoalan yang kerap dihadapi para perencana dan pelaksanan khususnya dalam pembangunan perkerasan jalan adalah cara menangani tanah dasar yang jelek yang akan digunakan sebagai lapis perkerasan. Karakteristik tanah sangat mempengaruhi besarnya daya dukung tanah terhadap beban diatasnya. Jika tanah dasarnya berupa tanah lempung maka merupakan material tanah dasar yang kurang baik, karena tanah lempung memiliki kuat geser yang sangat rendah, daya dukung yang rendah dan sifat kembang susut besar.

Salah satu cara untuk mengatasi permasalahan tersebut adalah dengan stabilisasi tanah. Stabilisasi tanah dimaksudkan untuk memperbaiki sifat-sifat tanah asli dengan cara menambahkan bahan tertentu yang mengakibatkan perubahan sifat-sifat tanah asli.

Penelitian ini mencoba memperbaiki karakteristik tanah lempung berlanau dengan menggunakan campuran pasir. Tujuan penelitian adalah untuk mengetahui pengaruh penambahan pasir terhadap kepadatan tanah dan daya dukung tanah lempung berlanau, dan perubahan nilai daya dukungnya atau California Bearing Ratio (CBR) tanah asli dan setelah distabilisasi dengan campuran pasir pada jalan Banjarparakan-Menganti Kecamatan Rawalo Kabupaten Banyumas.

\section{METODE PENELITIAN}

\subsection{Lokasi Penelitian}

Lokasi penelitian adalah pada ruas jalan Banjaraparakan-Menganti dengan lokasi amblasan terletak di grumbul Banjarwaru, Desa Banjarparakan, Kecamatan Rawalo, Kabupaten Banyumas, Provinsi Jawa Tengah. Ruas jalan Banjarparakan- Menganti merupakan jalan Kabupaten dengan kelas jalan III B, dengan panjang 1,9 $\mathrm{km}$ dan lebar perkerasan $4-7 \mathrm{~m}$ yang terdiri dari dua arah dan dua lajur.

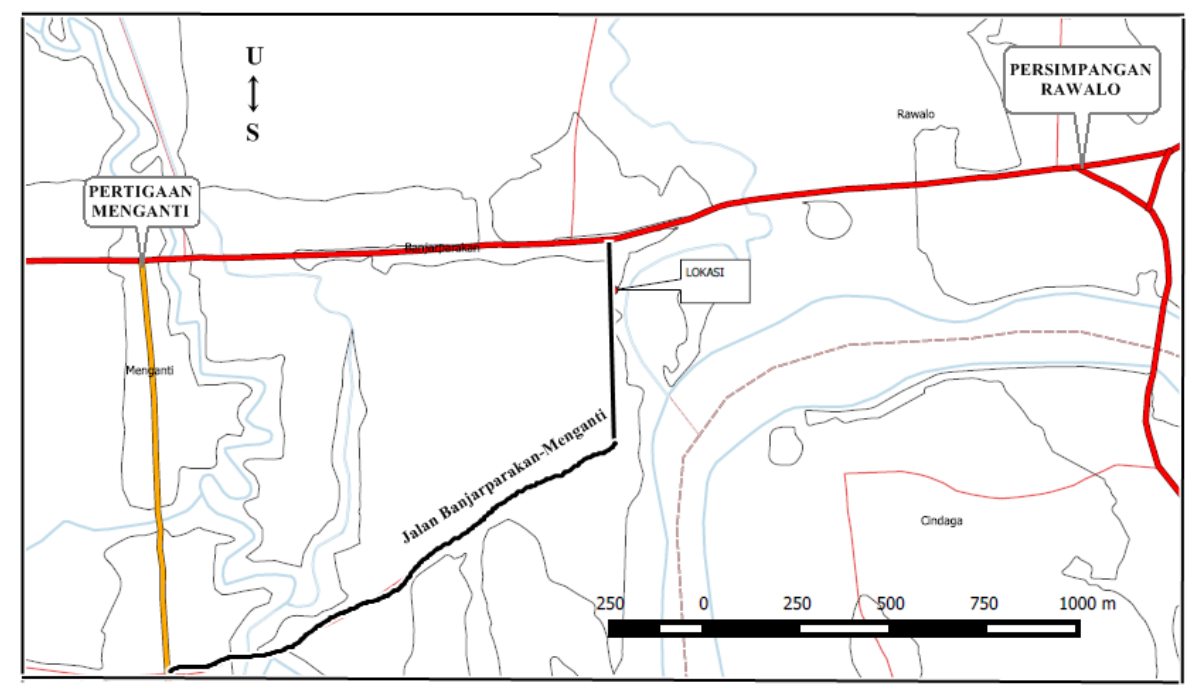

Gambar 3.1. Peta Lokasi Penelitian

Sumber : Dinas PU Kab. Banyumas, 2016 dalam Suryanto, 2017 


\subsection{Data}

Data primer berupa sampel tanah diambil dari lokasi berupa tanah terganggu (disturb soil), yaitu tanah yang telah terjamah atau terganggu oleh lingkungan luar. Sampel tanah diambil di tiga titik pada kedalaman $80 \mathrm{~cm}$ dari permukaan tanah pada badan jalan.

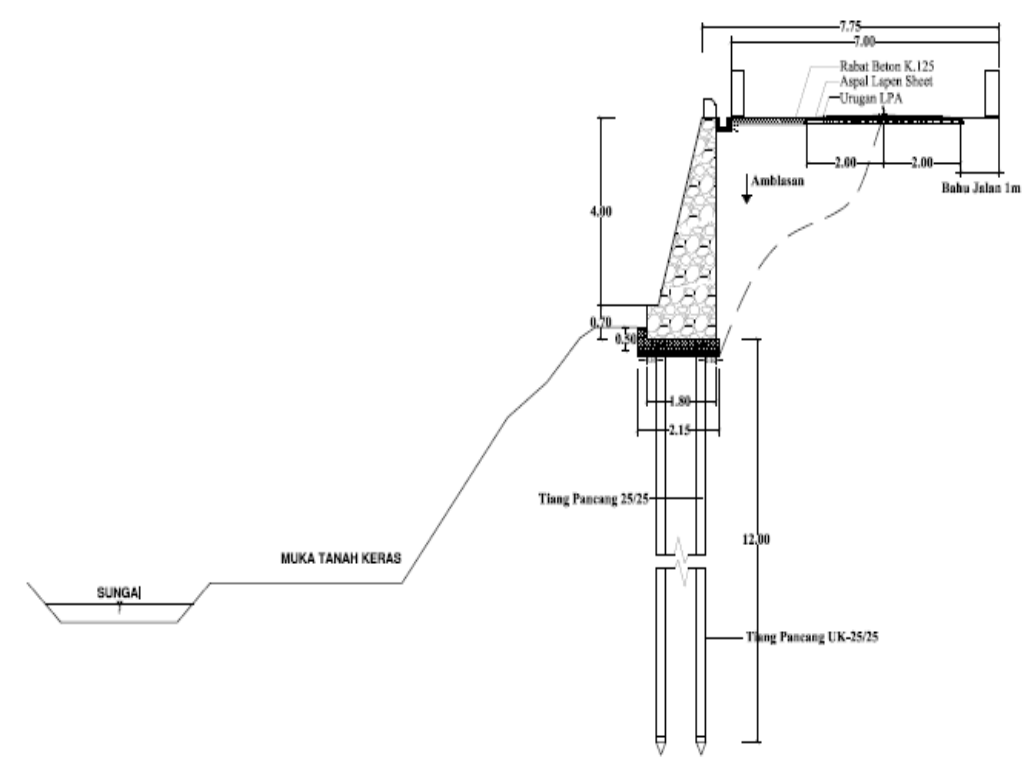

Gambar 3.2. Potongan melintang jalan

Sumber : Dinas PU Kab. Banyumas, 2014 dalam Suryanto, 2017

\subsection{Peralatan}

Peralatan yang digunakan dalam penelitian ini adalah alat uji saringan, uji berat jenis, uji kadar air, uji batas-batas konsistensi, dan lain-lain di Laboratorium Mekanika Tanah Fakultas Teknik dan Sains Universitas Muhammadiyah Purwokerto. Uji pemadatan dan uji CBR di lakukan di laboratorium PT. Putra Wirasaba Asli Kec. Wangon.

\subsection{Benda Uji}

Sampel tanah yang diuji adalah tanah asli dan tanah yang distabilisasi dengan pasir. Kadar pasir yang digunakan yakni $10 \%, 15 \%, 20 \%$, dan $25 \%$ dari berat tanah.

\subsection{Analisis Data}

Data hasil uji dianalisis untuk mendapatkan parameter-parameter kuat geser dan daya dukung tanah. Parameter yang didapat menggambarkan pengaruh penambahan pasir terhadap daya dukung tanah lempung.

\section{HASIL DAN PEMBAHASAN}

\subsection{Sifat Fisik Tanah}

Karakteristik tanah asli yang diambil dari Ruas Jalan Banjarparakan - Menganti dengan lokasi amblasan yang terletak di grumbul Banjarwaru, Desa Banjarparakan, Kecamatan Rawalo, Kabupaten Banyumas, Provinsi Jawa Tengah, diperoleh data yang tercantum dalam Tabel 1 berikut.

Tabel 1. Sifat Fisik Tanah Lempung (Soft Clay)

\begin{tabular}{clcc}
\hline No. & \multicolumn{1}{c}{ Pengujian } & Hasil Uji & Satuan \\
\hline 1 & Kadar Air & 27,11 & $\%$ \\
2 & Berat Jenis & 2,63 & \\
3 & Analisa Saringan & & $\%$ \\
& a. Lolos Saringan no. 8 & 99,99 & $\%$ \\
& b. Lolos Saringan no. 40 & 60,00 & $\%$ \\
& c. Lolos Saringan no. 200 & 57,74 & \\
4 & Batas - batas Attereberg & & $\%$
\end{tabular}




\begin{tabular}{cccc} 
& b. Batas Plastis (Plastic Limit) & 53,78 & $\%$ \\
5 & c. Indeks Plastisitas (Plasticity Index) & 11,55 & $\%$ \\
& Pemadatan (Modified Proctor) & & $\%$ \\
& a. Kadar Air Optimum & 36,10 & $\mathrm{gr} / \mathrm{cc}$ \\
& b. Berat Isi Kering Optimum & 1,29 & $\%$ \\
\hline Sumber : Hasil Analisis, 2021 & & 8,20 &
\end{tabular}

\subsection{Properti, batas-batas Atterberg dan Klasifikasi Tanah}

Kadar air tanah asli rata-rata sebesar $27,11 \%$. Hasil tersebut menunjukan bahwa tanah mengandung lempung, dengan kadar air besar dari $16 \%$. Berat jenis (Gs) diperoleh rata - rata sebesar 2,63\%, yang menunjukan sampel tanah termasuk dalam golongan tanah lanau anorganik dengan berat dan atau termasuk golongan tanah Lempung organik dengan berat jenis (Gs) antara 2,58 \% - 2,65\%.

Hasil uji batas-batas Atterberg dapat di lihat pada Tabel 4.3.

Tabel 2 Hasil Uji Batas-batas Atterberg Tanah Asli

\begin{tabular}{cccc}
\hline Jenis Tanah & $\begin{array}{c}\text { Batas Cair } \\
(\mathbf{L L}) \\
(\boldsymbol{\%})\end{array}$ & $\begin{array}{c}\text { Batas Plastis }(\mathbf{P L}) \\
(\boldsymbol{\%})\end{array}$ & $\begin{array}{c}\text { Indeks Plastisitas } \\
(\mathbf{P I}=\mathbf{L L}-\mathbf{P L}) \\
(\mathbf{\%})\end{array}$ \\
\hline Tanah Asli & 65,33 & 53,78 & 11,55 \\
\hline
\end{tabular}

Dengan nilai batas cair (LL), batas plastis (PL), dan indeks plastisitas (PI) seperti pada Tabel 2, dalam sistem klasifikasi tanah AASTHO (American Association of State Highway and Transportation Official) termasuk tanah berlempung dan penilaian sebagai tanah dasar kondisi biasa sampai jelek. Sedangkan berdasarkan sistem klasifikasi USCS maka tanah berbutir halus yang diuji termasuk kedalam kelompok $\mathrm{OH}$ yaitu tanah lempung organik dengan plastisitas sedang sampai tinggi.

Hasil uji dan analisa saringan didapat presentase butir lolos saringan No. 200 (0,074 mm) sebesar 57,74 \%, maka tanah dikategorikan kedalam golongan tanah berbutir halus (fine-grained soils).

\subsection{Hasil Uji Stabilisai Dengan Pasir Uji Berat Jenis (Gs)}

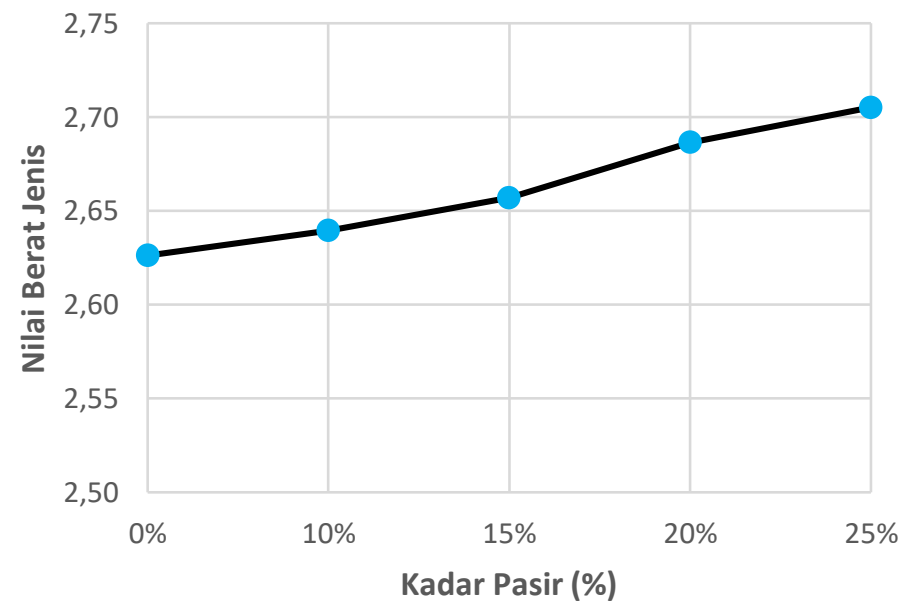

Gambar 1. Grafik Hubungan Campuran Pasir dan Berat Jenis Sumber : Analisis, 2021

Dari gambar 1 terlihat nilai berat jenis mengalami peningkatan meskipun tidak signifikan seiring dengan perubahan campuran pasir. 


\section{Batas Cair (LL)}

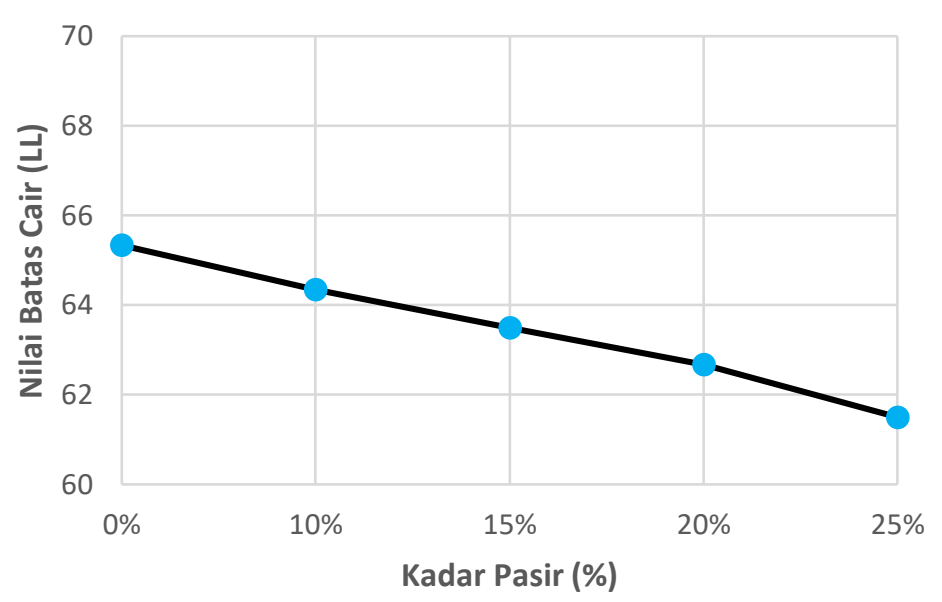

Gambar 2. Grafik Hubungan Campuran Pasir dan Batas Cair Sumber : Analisis, 2021

Hasil uji batas cair (LL) menunjukkan penurunan nilai batas cair (LL) seiring dengan naiknya prosentase $25 \%$ pasir.

\section{Batas Plastis (PL)}

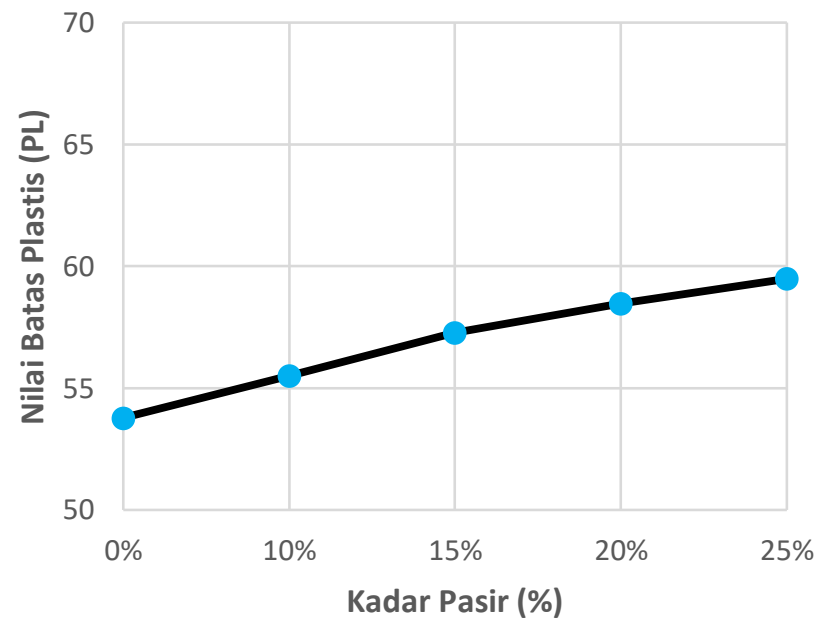

Gambar 3. Grafik Hubungan Campuran Pasir dan Batas Plastis Sumber : Analisis, 2021

Gambar 3 menunjukan bahwa nilai batas plastis (PL) mengalami kenaikan dengan bertambahnya prosentase campuran pasir.

\section{Indeks Plastisitas}

Tabel 3. Indek Plastisitas (PI)

\begin{tabular}{cccc}
\hline Pasir (\%) & LL & PL & PI \\
\hline $0 \%$ & 65,33 & 53,78 & 11,55 \\
$10 \%$ & 64,35 & 55,51 & 8,84 \\
$15 \%$ & 63,49 & 57,26 & 6,23 \\
$20 \%$ & 62,67 & 58,46 & 4,21
\end{tabular}




\begin{tabular}{crrr}
$25 \%$ & 61,50 & 59,48 & 2,02 \\
\hline Sumber : Analisis, 2021
\end{tabular}

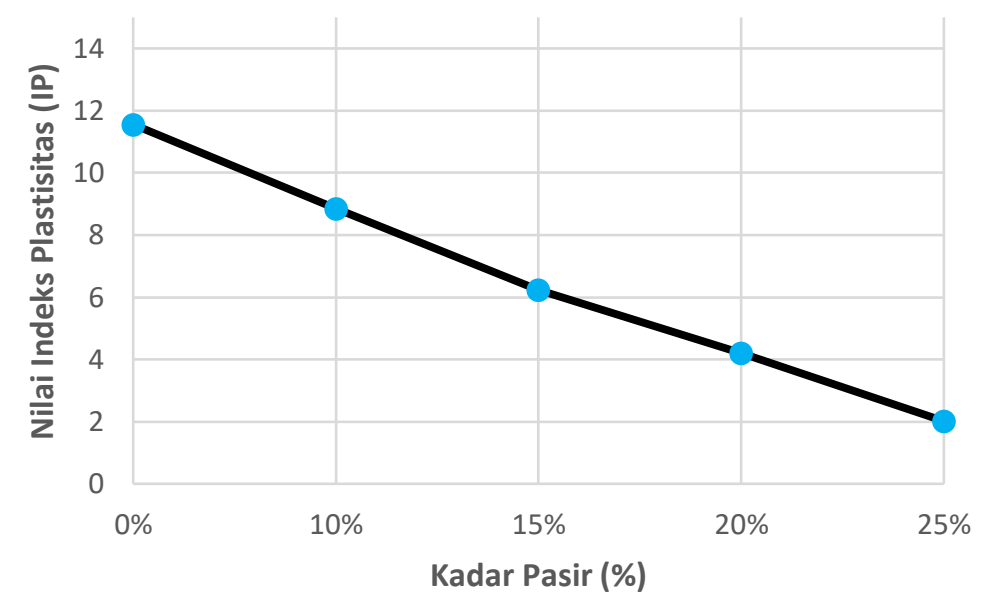

Gambar 4. Grafik Hubungan Campuran Pasir dan Indeks Plastisitas Sumber : Analisis, 2021

Dari gambar 4 terlihat bahwa nilai indeks plastisitas semakin menurun seiring bertambahnya pasir. Semakin besar nilai IP dari campuran tanah maka akan semakin besar pula potensi pengembangan tanah tersebut, dan sebaliknya.

\section{Uji Pemadatan Tanah}

Tabel 4. Nilai OMC (Optimum Moisture Content)

\begin{tabular}{cc}
\hline Campuran Pasir & Nilai OMC (\%) \\
\hline Tanah (Asli) & 36,10 \\
Tanah + pasir 10\% & 34,50 \\
Tanah + pasir 15\% & 32,60 \\
Tanah + pasir 20\% & 30,10 \\
Tanah + pasir 25\% & 28,05 \\
\hline Sumber : Analisis, 2021 &
\end{tabular}

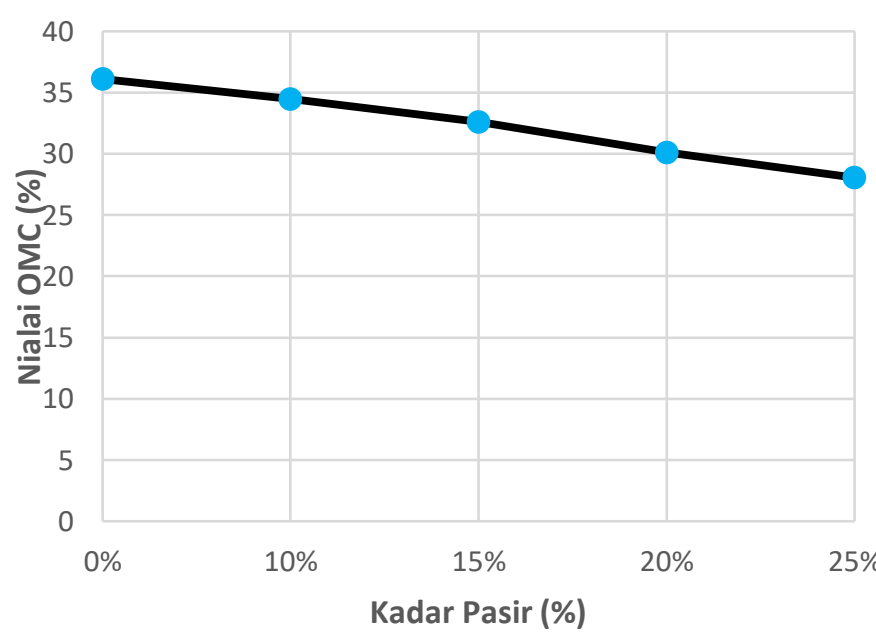

Gambar 5. Grafik Hubungan Campuran Pasir dan OMC (Optimum Moisture Content) (Sumber : Analisis, 2021) 
Hasil uji pemadatan seperti Tabel 4 dan Gambar 5 diatas dapat disimpulkan bahwa nilai OMC (Optimum Moistur Content) atau kadar air optimum mengalami penurunan setiap penambahan campuran pasirnya. Semakin banyak campuran pasir yang ditambahkan akan membuat nilai OMC (Optimum Moisture Content) menjadi lebih kecil.

Tabel 5. Nilai MDD (Maximum Dry Density)

\begin{tabular}{cc}
\hline Campuran Pasir & Nilai MDD $(\mathbf{g r} / \mathbf{c m})$ \\
\hline Tanah (Asli) & 1,29 \\
Tanah + pasir 10\% & 1,33 \\
Tanah + pasir 15\% & 1,35 \\
Tanah + pasir 20\% & 1,37 \\
Tanah + pasir 25\% & 1,39 \\
\hline Sumber $:$ Analisis, 2021
\end{tabular}

Sumber : Analisis, 2021

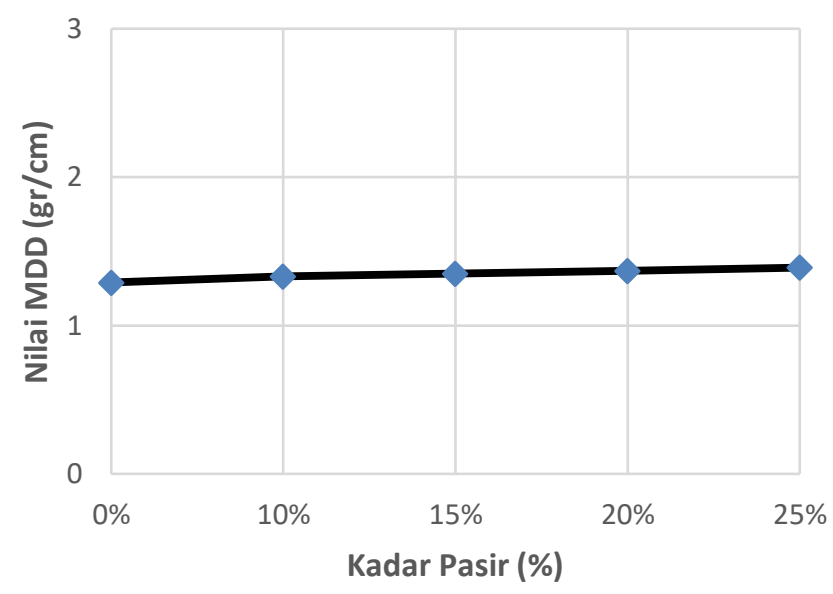

Gambar 6. Grafik Hubungan Campuran Pasir dan MDD (Maximum Dry Density)

Sumber : Analisis, 2021

Gambar 6 menunjukkan nilai MDD (Maximum Dry Density) atau berat isi kering maximum mengalami kenaikan seiring dengan penambahan campuran pasirnya. Jadi semakin banyak campuran pasir yang ditambahkan akan semakin besar nilai MDD yang diperolehnya

\section{Uji CBR (California Bearing Ratio)}

Tabel 6. Nilai CBR (California Bearing Ratio)

\begin{tabular}{cc}
\hline Campuran Pasir & Nilai CBR $(\boldsymbol{\%})$ \\
\hline Tanah (Asli) & 8,20 \\
Tanah + pasir 10\% & 10,00 \\
Tanah + pasir 15\% & 11,10 \\
Tanah + pasir 20\% & 12,30 \\
Tanah + pasir 25\% & 12,70 \\
\hline
\end{tabular}




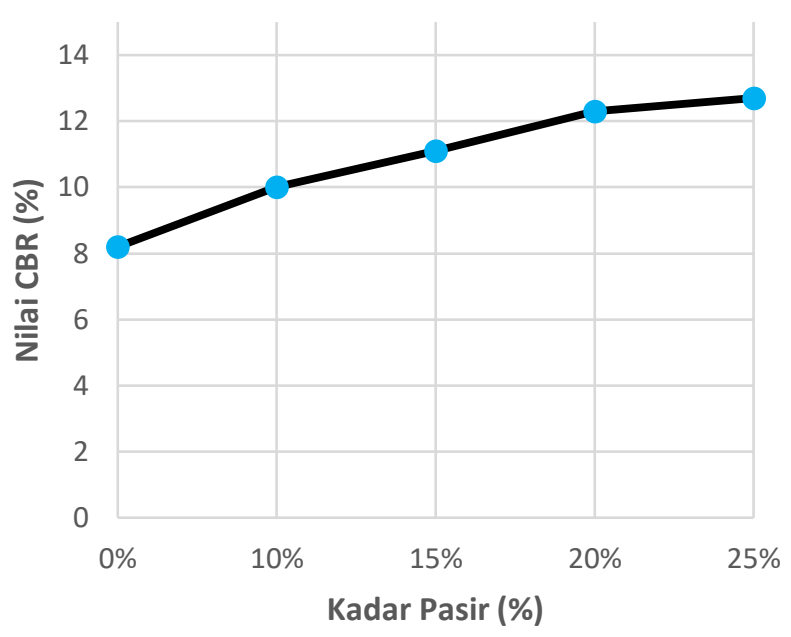

Gambar 7. Grafik Hubungan Campuran Pasir dan CBR (California Bearing Ratio) Sumber : Analisis, 2021

Dari Tabel 6 dan gambar 7 diatas menunjukan bahwa nilai CBR (California Bearing Ratio) mengalami kenaikan seiring dengan penambahan pasir. Naiknya nilai CBR menunjukan bahwa butir tanah dan pasir saling mengunci. Kenaikan nilai CBR yang lebih besar disetiap campurannya ini dipengaruhi oleh tingkat pemadatan yang dilakukan lebih kuat tiap campuran.

\section{KESIMPULAN}

1. Nilai kadar air optimum (OMC) mengalami penuruan disetiap variasi campuran pasir dan nilai kepadatan kering maksimum (MDD) mengalami kenaikan disetiap variasi campuran pasir.

2. Nilai CBR (California Bearing Ratio) mengalami kenaikan pada setiap penambahan pasir. Hasil tersebut menunjukan bahwa dengan penambahan pasir dapat meningkatkan nilai daya dukung tanah.

\section{DAFTAR PUSTAKA}

[1] Apriyono, Arwan, Sumiyanto, dan Adhe Noor. 2012. Buku Petunjuk Praktikum Mekanika Tanah. Laboratorium Mekanika Tanah. Program Studi Teknik Sipil. Fakultas Sains Dan Teknik. Universitas Jendral Soedirman. Purwokerto.

[2] Badan Standarisasi Nasional. 2012. SNI 1744:2012. Metode Uji CBR Laboratorium. Jakarta.

[3] Bowles, J.E. 1984. Sifat - Sifat Fisis Dan Geoteknis Tanah (Mekanika Tanah). Edisi Kedua. Jakarta: Erlangga.

[4] Das, B.M. 1995. Mekanika Tanah (Prinsip - Prinsip Rekayasa Geoteknis). Jilid 1. Jakarta: Erlangga.

[5] Ferdian, F. 2015. Pengaruh Penambahan Pasir Terhadap Tingkat Kepadatan Dan Daya Dukung Tanah Lempung Organik. JRSDD. Vol. 3, No. 1, Hal: $145-146$.

[6] Hardiyatmo, H.C. 2002. Mekanika Tanah I. Edisi Ketiga. Yogyakarta: Gadjah Mada University Press.

[7] Hasriana. 2018. Bearing capacity improvement of soft soil subgrade layer with Bio Stabilized Bacillus Subtilis. MATEC Web of Conferences 181, 01001 (2018).

[8] Ozdemir, M.A. 2016. Improvement in Bearing Capacity of a Soft Soil by Addition of Fly Ash. Procedia Engeneering. Volume 143, 2016, Pages 498 - 505.

[9] Prasenda, C. 2015. Pengaruh Penambahan Pasir Terhadap Tingkat Kepadatan Dan Daya Dukung Tanah Lempung Lunak. JRSDD. Vol. 3, No. 1, Hal: 91 - 102.

[10] Suryanto, B.E. 2017. Analisis Karakteristik Tanah Dasar Pada Segmen Jalan Amblas Jalan Banjarparakan-Menganti Kecamatan Rawalo-Kabupaten Banyumas. Skripsi. Fakultas Teknik dan Sains. Universitas Muhammadiyah Purwokerto. Purwokerto 